\title{
EVALUATION OF DIABETES SELF-MANAGEMENT EDUCATION IN PATIENTS WITH CONCOMITANT CHRONIC KIDNEY DISEASE
}

10.36740/WLek202010112

\author{
Oleksii M. Korzh \\ KHARKIV MEDICAL ACADEMY OF POSTGRADUATE EDUCATION, KHARKIV, UKRAINE
}

\begin{abstract}
The aim: Was to evaluate the quality of DSME provided by primary care physicians to people with diabetes mellitus.

Materials and methods: A descriptive cross-sectional study was conducted among 120 primary care physicians. The quality of diabetes self-management training provided by physicians was assessed on a personal scale of 39 Likert questions obtained from the American Association of Diabetes Educators in seven areas of diabetes self-monitoring. The Cronbach's reliability coefficient for each domain / subscale was $\geq 0.7$. The data were analyzed using an independent selective t-test and one-way ANOVA.

Results: More than half of the doctors provided "inadequate quality" of diabetes self-management in all areas. Doctors had the highest average score in the domain of "drug intake" (4.46 \pm 0.61$)$. Average scores in the "problem-solving domain" (3.52 \pm 0.63$)$ and " being active domain" (3.46 \pm 0.75$)$ were low. The quality of DSME provided by physicians was not related to any of the characteristics of the physician.

Conclusions: The quality of doctors' communication on DSME in this study was suboptimal. Most adequately informed cases of diabetic behavior associated with self-management have been associated with reduced risk factors and an orientation towards disease. Thus, training of primary care physicians in diabetic self-management is recommended because of the key role that these doctors play in managing diabetes.
\end{abstract}

KEY WORDS: primary care, family physicians, patient-physician communication, diabetes self-management education

Wiad Lek. 2020;73(10):2170-2174

\section{INTRODUCTION}

Type 2 diabetes mellitus (DM2) is a disease with a high prevalence and a significant effect of mortality and morbidity. Increasing the prevalence of the disease requires the introduction of new strategies that promote patient self-control. Patient education is essential for this, but it takes a lot of time $[1,2]$.

Diabetes self-management education (DSME) is recognized as an integral aspect of helping people with diabetes in combination with pharmacotherapy, which can include several medications and dosing algorithms. DSME is a process that helps people make decisions that lead to improved variables, such as knowledge, attitudes and self-efficacy, as well as improved healthy behavior and clinical outcomes. DSME is defined as a systematic intervention that involves the active participation of a person in the self-monitoring of health parameters and / or decision-making with the use of knowledge and skills [3, 4].

The goal of DSME is to create opportunities for people with diabetes to be informed and motivated to continuously participate in effective methods and methods of self-monitoring of diabetes. This should enable patients to more actively manage their lifestyle, moving to more healthy habits and improving diet, exercise, proper use of drugs and relationships with their doctor, as well as with their relatives and friends $[5,6]$.

Health systems should provide more efficient and coordinated care for patients with chronic diseases, and this should be aimed at reducing the rate of deterioration and improving the quality of life of patients and their families / caregivers. In this regard, primary care plays an important role $[7,8]$. In many medical institutions in Ukraine there are no structured diabetes self-control programs, and the only way to ensure DSME appears when people with diabetes are in the office of their family doctors. Thus, the purpose of this article was to assess the quality of DSME provided by primary care physicians during medical meetings with people with type 2 diabetes. This can help develop the DSME protocol reference manual for primary care physicians and develop patient self-monitoring tools.

\section{THE AIM}

The aim was to evaluate the quality of DSME provided by primary care physicians to people with diabetes mellitus.

\section{MATERIALS AND METHODS}

This study was prospective, conducted in the centers of primary medical care in Kharkiv (clinical bases of the Kharkov Medical Academy of Postgraduate Education) in the period from January 2017 to January 2019.

The study was conducted in accordance with international standards of bioethics (Council of the European Convention on Human Rights and Biomedicine) and the recommendations of the Committee on Bioethics of 
the Ministry of Health of Ukraine. All patients signed an informed consent to participate in the study. This study was approved by the Ethics Commission of the Kharkov Medical Academy of Postgraduate Education of the Ministry of Health of Ukraine (Kharkiv, UA).

This included primary care physicians at various levels of professional qualifications in the specialty of family medicine. These included family doctors, residents of family medicine, and family medicine counselors / fellows.

It was a descriptive crossover study. The study was conducted mainly with a quantitative approach using a self-managed questionnaire.

The data was obtained from respondents using a self-structured questionnaire developed by the authors. The information received included the demographic characteristics of the respondents and the quality of DSME, which they gave to people with SD. Demographic characteristics included age, gender, professional qualifications, work experience, DSME program in the context of the respondents' practice, awareness of diabetes self-control, and DSME formal training.

The quality of informing respondents about diabetic self-control was assessed using our own scale, developed by the American Association of Diabetes Educators 7 areas (AADE7) of self-care behaviors necessary for effective self-control of diabetes. , AADE7 was defined to guide the DSME process and help people with diabetes to achieve behavior change. The seven types of self-care behaviors necessary for successful and effective diabetes self-control are healthy eating, activity, medication, monitoring, problem solving, risk reduction, and healthy survival.

The content of the seven areas of self-care behavior in AADE7 was used to develop a 39-point Likert-type questionnaire. These Likert elements were divided into Likert subsciled up, grouped into seven domains. Answers to each question never, rarely, sometimes, often, always. Answers were never rated (1), rarely (2), sometimes (3), often (4), always (5). The content of the accuracy of the scale was evaluated by three experts on diabetes (a family doctor with a special interest in diabetes and two endocrinologists). The final form consisted of 39 Likert-type questions in seven subscale: healthy eating (5 Likert items); be active (7 Likert items), take medicine (6 Likert items), monitor (5 Likert items), solve problems (6 Likert items), reduce risks (6 Likert items) and cope with health (4 Likert items).

A total of 120 doctors were included. The questionnaire was sent to them, and they filled it out without any consultation between them within 10 minutes.

\section{STATISTICAL ANALYSIS}

The data was analyzed using the Statistical Package for Social Sciences TM (IBM Corp, Armonk, NY, USA). The frequency distribution of the data was analyzed to determine normality. Data was presented using the relevant tables. Descriptive analyzes, such as frequency and mean, were obtained to summarize the data. The average score of the respondents, the total average score for the domain and the total aver- age score were calculated. Using the t-test of independent samples, the mean values of dichotomous categorical independent variables were compared. As an extension of the Student t-test for independent samples, one-way ANOVA was used when there were two or more independent groups. The significance level was set at $\mathrm{p} \leq 0.05$.

\section{RESULTS}

Of the 120 distributed twenty questionnaires in 13 questionnaires there was no data, which gave a fill factor of $89.2 \%$. The mean age was $44.25 \pm 5.71$ years. Most respondents $(92.40 \%)$ practiced for more than five years.

The frequency histogram of the data showed that the data were normally distributed. The subscale / domains had good internal consistency (Cronbach's alpha $\geq 0.70$ ), which indicates that the elements in each subscale / domain measured the unitary construction (Table 1). The average scores of respondents in all domains were first compiled in order to obtain a model for presenting the results of the qualitative communication of respondents with diabetes while managing diabetes themselves. The average scores of respondents in each domain were divided into two categories using an average score that corresponded to the 50th percentile as a cut-off point for each domain.

The quality of informing respondents about the methods of self-control for people with diabetes was classified as "inadequate" if the respondent had an average score lower than the 50th percentile of the average domain score, and "adequate" if it was greater than or equal to the 50th percentile of the mean score of the domain. The boundary average points for domains, the average interval of points for adequate and inadequate quality of self-management communication for domains, and the percentage of participants with adequate and inadequate quality for each area of self-government behavior are shown in Table 1 . More than half of the participants fell into the category of "inadequate" self-developed average threshold indicators values in all seven areas (see Table 1).

Of the 39 items, the average marks of 19 items, marked with an asterisk in Table 2, fall into the category of "inadequate" independently developed threshold values for each domain. The drug-taking domain had the highest average score $(4.46 \pm 0.61)$. Problem solving and being active domains had low average values of $3.52 \pm 0.63$ and $3.46 \pm 0.75$, respectively. The behavioral element "Check blood glucose before and after exercise" had the lowest average score $(2.66 \pm 1.31)$ (see Table 2).

An independent sample t-test showed that there was no connection between the quality of respondent's communication about self-managed diabetes and gender based on the total total average score of respondents $(t=0.79$; $\mathrm{p}=0.44$ ). However, female respondents had a higher average score than their male counterparts in problem-solving $(\mathrm{t}=2.73 ; \mathrm{p}=0.03)$ based on an analysis of the average score by domain.

There was no relationship between the quality of informing respondents about the behavior of diabetic patients and 
Table I. Summary descriptions of the scale used for data collection and the self-developed cut-off points for the model

\begin{tabular}{|c|c|c|c|c|c|c|}
\hline \multirow{2}{*}{ Domains } & \multirow{2}{*}{$\begin{array}{l}\text { Reliability } \\
\text { coefficient of } \\
\text { the domains } \\
\text { (Cronbach's } \\
\text { alpha) }\end{array}$} & \multirow{2}{*}{$\begin{array}{c}\text { Domain } \\
\text { mean } \\
\text { score } \\
\text { range }\end{array}$} & \multirow{2}{*}{$\begin{array}{c}\text { Domain } \\
\text { mean } \\
\text { score }\end{array}$} & \multirow{2}{*}{$\begin{array}{l}\text { Domain } \\
50 \text { th } \\
\text { percentile } \\
\text { score (cut- } \\
\text { off score) }\end{array}$} & \multicolumn{2}{|c|}{$\begin{array}{l}\text { Mean score interval for adequate and inadequate } \\
\text { quality of communication using 50th percentile }\end{array}$} \\
\hline & & & & & $\begin{array}{c}\text { Inadequate } \\
\text { (<50th percentile) }\end{array}$ & $\begin{array}{c}\text { Adequate } \\
\text { ( } \geq \text { 50th percentile) }\end{array}$ \\
\hline Healthy eating & 0.81 & $2.21-5.00$ & $4.22 \pm 0.65$ & 4.22 & $2.20-4.21(53.60 \%)$ & $4.22-5.00(46.40 \%)$ \\
\hline Being active & 0.82 & $1.87-5.00$ & $3.59 \pm 0.73$ & 3.76 & $1.86-3.75(59.20 \%)$ & $3.76-5.00(40.80 \%)$ \\
\hline Monitoring & 0.90 & $2.41-5.00$ & $4.23 \pm 0.71$ & 4.28 & $2.40-4.27(53.10 \%)$ & $4.28-5.00(46.90 \%)$ \\
\hline Taking medication & 0.87 & $2.01-5.00$ & $4.38 \pm 0.54$ & 4.49 & $2.00-4.48(59.80 \%)$ & $4.49-5.00(40.20 \%)$ \\
\hline Problem- solving & 0.88 & $1.34-5.00$ & $3.66 \pm 0.75$ & 3.71 & $1.33-3.70(56.10 \%)$ & $3.71-5.00(43.90 \%)$ \\
\hline Reducing risks & 0.82 & $2.54-5.00$ & $4.31 \pm 0.52$ & 4.37 & $2.50-4.36(60.30 \%)$ & $4.37-5.00(39.70 \%)$ \\
\hline Healthy coping & 0.86 & $2.53-5.00$ & $4.32 \pm 0.59$ & 4.31 & $2.50-4.30(50.90 \%)$ & $4.31-5.00(49.10 \%)$ \\
\hline
\end{tabular}

Table II. Item mean and domain mean of the respondents

\begin{tabular}{|c|c|c|c|}
\hline AADE domains & Behavioural items & Item (mean \pm SD) & Domain mean \pm SD \\
\hline \multirow{5}{*}{ Healthy eating } & The foods that are best to eat or avoid & $4.65 \pm 0.78$ & \multirow{5}{*}{$4.32 \pm 0.75$} \\
\hline & When and how much to eat & $4.44 \pm 0.95$ & \\
\hline & Developing a practical meal plan ${ }^{\mathrm{a}}$ & $3.79 \pm 1.11$ & \\
\hline & Preventing high or low blood sugar & $4.60 \pm 0.78$ & \\
\hline & Setting goals for healthy eating ${ }^{a}$ & $4.01 \pm 0.96$ & \\
\hline \multirow{7}{*}{ Being active } & Importance of exercise in DM management & $4.49 \pm 0.46$ & \multirow{7}{*}{$3.46 \pm 0.75$} \\
\hline & Daily exercise for 30 minutes at least 5 times a week & $4.07 \pm 0.73$ & \\
\hline & Don't overdo the exercise ${ }^{\mathrm{a}}$ & $3.58 \pm 1.02$ & \\
\hline & Check blood glucose before and after exercise ${ }^{a}$ & $2.66 \pm 1.31$ & \\
\hline & Keep track of your activity ${ }^{a}$ & $3.32 \pm 1.04$ & \\
\hline & Join a gym and/or league and engage in a sport ${ }^{a}$ & $3.08 \pm 1.05$ & \\
\hline & Mix the exercise - try a few different things ${ }^{a}$ & $3.10 \pm 1.09$ & \\
\hline \multirow{5}{*}{ Monitoring } & The way to use a blood sugar (glucose) meter ${ }^{a}$ & $4.20 \pm 0.86$ & \multirow{5}{*}{$4.29 \pm 0.71$} \\
\hline & When to check blood glucose and what the values mean & $4.32 \pm 0.82$ & \\
\hline & How to record blood glucose results & $4.42 \pm 0.86$ & \\
\hline & What to do when the values are not normal ${ }^{a}$ & $4.28 \pm 0.94$ & \\
\hline & Regular blood pressure, cholesterol and weight check ${ }^{a}$ & $4.24 \pm 0.92$ & \\
\hline \multirow{6}{*}{$\begin{array}{c}\text { Taking } \\
\text { medication }\end{array}$} & Knowing their medications & $4.83 \pm 0.66$ & \multirow{6}{*}{$4.46 \pm 0.61$} \\
\hline & The reason for using the medications & $4.87 \pm 0.62$ & \\
\hline & How the medications are used & $4.59 \pm 0.74$ & \\
\hline & Knowing some of the side effects of the medications ${ }^{a}$ & $4.11 \pm 0.93$ & \\
\hline & Knowing what to do in the event of side effects ${ }^{\mathrm{a}}$ & $4.34 \pm 0.98$ & \\
\hline & Knowing what to do if the medications are forgotten ${ }^{a}$ & $3.90 \pm 1.22$ & \\
\hline \multirow{6}{*}{ Problem-solving } & Problems may arise even when they follow self-management of DM & $3.58 \pm 0.73$ & \multirow{6}{*}{$3.52 \pm 0.63$} \\
\hline & Don't beat themselves up when problem occurs & $3.72 \pm 0.75$ & \\
\hline & Think about what was different when problems arise $\mathrm{a}^{\mathrm{a}}$ & $3.38 \pm 0.89$ & \\
\hline & Learning from the problem when it happens ${ }^{a}$ & $3.36 \pm 1.06$ & \\
\hline & Discuss possible solutions with your doctor & $3.81 \pm 0.84$ & \\
\hline & Try the new solution and evaluate if it is working ${ }^{a}$ & $3.43 \pm 1.01$ & \\
\hline \multirow{6}{*}{ Reducing risk } & Don't smoke & $4.73 \pm 0.71$ & \multirow{6}{*}{$4.29 \pm 0.62$} \\
\hline & See your doctor regularly & $4.84 \pm 0.56$ & \\
\hline & Visit the eye doctor at least once a year ${ }^{\mathrm{a}}$ & $3.98 \pm 1.04$ & \\
\hline & The need for regular dental check-up ${ }^{\mathrm{a}}$ & $3.22 \pm 1.17$ & \\
\hline & Take care of your feet & $4.54 \pm 0.83$ & \\
\hline & Report any abnormal feelings to the doctor & $4.57 \pm 0.76$ & \\
\hline \multirow{4}{*}{ Coping } & Seeking support from family and friends ${ }^{a}$ & $4.18 \pm 0.84$ & \multirow{4}{*}{$4.38 \pm 0.69$} \\
\hline & Being active & $4.61 \pm 0.74$ & \\
\hline & Thinking positive & $4.45 \pm 0.71$ & \\
\hline & Being good to yourself & $4.33 \pm 0.81$ & \\
\hline
\end{tabular}

a - Asterisks indicate items with mean scores that fall in the 'inadequate' category based on the domain's cut-off 
Table III. Association between quality of respondents'communication of diabetes self-management and age group, length of practice and professional status

\begin{tabular}{|c|c|c|c|c|c|}
\hline \multirow{2}{*}{ Variable } & \multirow{2}{*}{ Category } & \multirow{2}{*}{ Frequency } & \multicolumn{3}{|c|}{ Summated total mean score } \\
\hline & & & Mean \pm SD & $\mathbf{F}$ & Sig. (2-tailed) \\
\hline \multirow{3}{*}{ Age group } & Young & 31 & $4.11 \pm 0.52$ & \multirow{3}{*}{0.44} & \multirow{3}{*}{0.71} \\
\hline & Middle aged & 75 & $4.09 \pm 0.48$ & & \\
\hline & Elderly & 1 & 4.00 & & \\
\hline \multirow{4}{*}{ Length of practice } & $<5$ years & 8 & $4.00 \pm 0.63$ & \multirow{4}{*}{0.04} & \multirow{4}{*}{0.95} \\
\hline & $5-10$ years & 23 & $3.98 \pm 0.50$ & & \\
\hline & $11-15$ years & 63 & $4.11 \pm 0.54$ & & \\
\hline & $\geq 16$ years & 13 & $4.15 \pm 0.34$ & & \\
\hline \multirow{3}{*}{ Professional status } & Family physicians & 70 & $4.09 \pm 0.55$ & \multirow{3}{*}{0.41} & \multirow{3}{*}{0.82} \\
\hline & Resident & 31 & $4.02 \pm 0.48$ & & \\
\hline & Consultant/Fellow & 6 & $4.29 \pm 0.46$ & & \\
\hline
\end{tabular}

formal training in diabetes self-control based on an analysis of the total overall average using an independent sample $\mathrm{t}$-test $(\mathrm{t}=1.86 ; \mathrm{p}=0.23)$. However, based on the average score for a specific domain, the average score of participants who received formal training in self-treatment of diabetes was higher than among those who did not receive formal training in the field of healthy nutrition $(\mathrm{t}=2.54, \mathrm{p}=0,04)$.

There was no connection between the quality of informing respondents about diabetes self-control and the presence of group counseling programs on diabetes self-control in terms of respondents' practice, based on an analysis of the average score in a particular area and a total analysis of the total average score.

The results of the one-way ANOVA test showed that there was no relationship between the quality of respondent's communication about diabetes, self-management and age group, practice duration and professional status based on the average score for a specific domain and the total total average score (Table 3).

\section{DISCUSSION}

Family physicians directly communicate with their patients during clinical encounters across numerous settings, and research indicates that patients highly value recommendations provided by their physicians [9.10]. However, data further indicate that lifestyle counseling does not routinely occur in physicians' offices, thereby representing a lost opportunity [11].

Many factors contribute to this situation. Physicians report they lack the necessary knowledge about how various diet and physical activity regimens affect specific medical conditions $[11,12]$. Many doctors also say they lack the competencies needed to perform lifestyle counseling effectively. Although a large and convincing body of scientific evidence supports the benefits of a healthy diet, physical activity, and nonsmoking in non-communicable diseases prevention and management, dissemination of this knowledge during medical training and continuing medical education is marginal compared with the time and resources devoted to pharmacological treatment $[14,15]$.

Consequently, family physicians feel incompetent and lack confidence to provide adequate lifestyle counseling in the domains of physical activity, nutrition, weight management, and tobacco use.

Another important barrier to lifestyle counseling is that family physicians are often skeptical about their patients' receptivity to such advice, believing that "patients won't change anyway," and that lifestyle counseling, therefore, is not worth the time required, despite literature showing that physicians' advice is effective in encouraging patients to change behaviors [16]. Finally, limitations in time during clinical encounters and low or nonexistent reimbursement for lifestyle counseling also negatively impact a physician's perspective about the value of this practice $[15,17]$.

Our intent is not to assert that physicians should know everything about behavioral sciences, nutrition, physical activity, and tobacco use as determinants of health and diseases, or to suggest that they become experts in all of those fields. Instead, we recommend that physicians become comfortable with engaging in conversations with their patients to initiate the behavior modification process, to make assessments, provide basic advice, and encouragement toward a healthy lifestyle, and to refer patients to other healthcare professionals in the appropriate situations. Many institutions are leaders in medical education for health behavior and lifestyle counseling, but wider implementation of lifestyle counseling education is needed nationally to ensure that family physicians are well prepared to address the main health issues of the 21 st century.

\section{CONCLUSIONS}

The quality of communication of doctors with diabetes in this study is suboptimal. The primary care physicians in this study inadequately described the behavior of the diabetics administering them. The determinants of the quality of self-monitoring information provided by primary care physicians to patients may be more related to the training of staff in diabetes self-monitoring.

This study is relevant to both primary care physicians and the health care system. An individual primary care physician should strive to adequately report self-management behavior that is not only disease-oriented, but also problem-solving. Physicians should inform people with diabetes about the formal and informal support available 
in their practice. The organization of the health care system should stimulate the exchange of information to facilitate self-management among people with diabetes. Public and private medical institutions should encourage periodic training of primary care physicians, who often act as diabetes educators. This can improve self-service practices and glycemic control among people with type 2 diabetes.

\section{REFERENCES}

1. Federation I.D. IDF diabetes atlas -8th edition 2017. 2017. http://www. diabetesatlas.org/.

2. Gaede P., Lund-Andersen H., Parving H.H. et al. Effect of a multifactorial intervention on mortality in type 2 diabetes. $\mathrm{N}$ Engl J Med. 2008;358(6):580-91.

3. Inzucchi S.E., Bergenstal R.M., Buse J.B. et al. Management of hyperglycemia in type 2 diabetes: a patient-centered approach: position statement of the American Diabetes Association (ADA) and the European Association for the Study of Diabetes (EASD). Diabetes Care. 2012;35(6):1364-79.

4. Diabetes Canada Clinical Practice Guidelines Expert C, Punthakee Z, Goldenberg R, et al. Definition, Classification and Diagnosis of Diabetes, Prediabetes and Metabolic Syndrome. Can J Diabetes. 2018;42(1):5-10.

5. Brownrigg J.R., Hughes C.O., Burleigh D. et al. Microvascular disease and risk of cardiovascular events among individuals with type 2 diabetes: a population- level cohort study. Lancet Diabetes Endocrinol. 2016;4(7):588-97.

6. Force M., Ryden L., Grant P.J. et al. ESC Guidelines on diabetes, prediabetes, and cardiovascular diseases developed in collaboration with the EASD: the Task Force on diabetes, pre-diabetes, and cardiovascular diseases of the European Society of (ardiology (ESC) and developed in collaboration with the European Association for the Study of Diabetes (EASD). Eur Heart J. 2013;34(39):3035-87.

7. Piepoli M.F., Hoes A.W., Agewall S. et al. 2016 European Guidelines on cardiovascular disease prevention in clinical practice: The Sixth Joint Task Force of the European Society of Cardiology and Other Societies on Cardiovascular Disease Prevention in Clinical Practice (constituted by representatives of 10 societies and by invited experts) Developed with the special contribution of the European Association for Cardiovascular Prevention \& Rehabilitation (EACPR). Eur Heart J. 2016;37(29):2315-81.

8. American Diabetes Association. Standards of Medical Care in Diabetes-2018. Diabetes Care. 2018;41(1).

9. Lean M.E., Leslie W.S., Barnes A.C. et al. Primary care-led weight management for remission of type 2 diabetes (DiRECT): an open-label, cluster-randomised trial. Lancet. 2018;391(10120):541-51.
10. Vijayakumar S., Vaduganathan M., Butler J.Glucose-Lowering Therapies and Heart Failure in Type 2 Diabetes Mellitus: Mechanistic Links, Clinical Data, and Future Directions. Circulation. 2018;137(10):1060-73.

11. Korzh 0., Tsodikova 0 . Improving doctor-patient communication in a primary care setting. Practica Medicala.2019;14(64):13-17.

12. Anhang Price R., Elliott M.N., Zaslavsky A.M., Hays R.D. et al. Examining the role of patient experience surveys in measuring health care quality. Med Care Res Rev. 2014; 71:522-554.

13. Hersh L., Salzman B., Snyderman D. Health literacy in primary care practice. American Family Physician. 2015;92(2):118-124.

14. Korzh 0. , Krasnokutskiy S. Significance of education and selfmanagement support for patients with chronic heart failure in family physician practice. Fam Med Prim Care Rev. 2016; 18(4): 432-436. doi: 10.5114/fmpcr.2016.63697.

15. Haun J.P., French N., Campbell D., Bradham R. etal.Association between health literacy and medical care costs in an integrated healthcare system: a regional population based study. BMC Health Service Research. 2015;15:249-260.

16. AhlqvistE., Storm P., Karajamaki A. et al. Novel subgroups of adult-onset diabetes and their association with outcomes: a data-driven cluster analysis of six variables. Lancet Diabetes Endocrinol. 2018;6(5):361-9.

17. Maguire P., Pitceathly C. Key communication skills and how to acquire them. BMJ. 2002; 325:697-700.

\section{ORCID and contributionship:}

Oleksii M. Korzh: 0000-0001-6838-4360 A,B,C,D,E,F

\section{Conflict of interest:}

The Author declare no conflict of interest.

\section{CORRESPONDING AUTHOR \\ Oleksii M. Korzh \\ Kharkiv Medical Academy of Postgraduate Education \\ 275 Moskovskiy Av., 61006 Kharkiv, Ukraine \\ tel: +380506157195 \\ e-mail: okorzh2007@gmail.com}

Received: 23.10 .2019

Accepted: 27.08 .2020

A - Work concept and design, B - Data collection and analysis, C - Responsibility for statistical analysis, D-Writing the article, $\mathbf{E}-$ Critical review, $\mathbf{F}-$ Final approval of the article 